\title{
The role of morphological markedness in inclusive/exclusive pronouns*
}

\author{
BEATA MOSKAL \\ University of Connecticut, Storrs
}

\section{$1 \quad$ Introduction}

In this paper, I address the role of markedness in the inclusive/exclusive distinction in pronouns by taking into account evidence from suppletion in the context of the inclusive and exclusive. I will argue that there is an asymmetry in that pronouns can supplete in the context of solely the inclusive but not in the context of solely the exclusive, an observation that derives from markedness considerations. Suppletion refers to the phenomenon where a single lexical item is associated with two phonologically unrelated forms, the choice of form depending on the morphosyntactic context. A few canonical examples of suppletion in English are found in (1).

$$
\begin{aligned}
& \text { good - better - best } \\
& \text { bad - worse }- \text { worst } \\
& \text { go - went }
\end{aligned}
$$

In particular, compare the suppletive good-better-best paradigm with the regular smart-smartersmartest paradigm. In the latter, we observe that the root remains the same throughout the paradigm, viz. smart. In contrast, in the suppletive paradigm, we see that the root in the adjective surfaces as good, whereas in the context of the comparative and superlative we observe be(tt). Specifically, suppletion refers to a phonologically distinct realisation of a particular item in a particular context (see Corbett 2007 on specific criteria for canonical suppletion). In this case, the root of the lexical item GOOD is realised as good when it is the adjectival form but surfaces as $b e(t t)$ in the context of the comparative (and superlative). Though rare in absolute terms, suppletion (of lexical items) is frequently observed across languages in a (small) number of items (Hippisley e.a. 2004). ${ }^{1}$

Turning to the inclusive-exclusive distinction, this grammatical contrast traditionally captures the difference whether the addressee (or addressees, represented by 2 below) are included or excluded from the set of referents which also contains the speaker, $1 .{ }^{2}$ This can be represented as in (2), where 3 represents those who are neither speaker nor hearer (i.e. third person referents):

* Many thanks to Peter Smith for invaluable discussion on the ideas expressed here. All errors are mine.

1 An important question concerns what does and what does not count as suppletion (Corbett 2007). Here, I take the criterion for noun suppletion to be singular-plural pairs identified as suppletive in prior literature, where these are strongly suppletive, i.e., not plausibly related by (possibly idiosyncratic) phonological (readjustment) rule(s).

2 In the following I use this traditional use of inclusive/exclusive; for more distinctions involving inclusion or exclusion of persons, see Siewerska \& Bakker (2005). 
Inclusive: $1+2(+3)$

Exclusive: $1+3$

When the inclusive is used, the addressee is crucially included, while the exclusive indicates that the addressee is excluded. This is a distinction that is frequently seen across languages (Cysouw 2003, Filimonova 2005). While the inclusive/exclusive distinction can be found in verb agreement affixes and possessive affixes as well, I here limit myself to inclusive/exclusive plural independent pronouns, such as in So (3).

\begin{tabular}{llll}
\multicolumn{2}{c}{ So (Serzisko 1992) } & & \\
& SINGULAR & & PLURAL \\
1 & aya & EXCL & inia \\
& & INCL & isia \\
& & piya & pitia \\
3 & ica & & itia
\end{tabular}

Furthermore, the inclusive-exclusive distinction is also attested in other numbers, such as the dual and trial (Siewerska 2004), but again I leave this topic to future research and focus only on plural forms with the inclusive/exclusive distinction.

In the following, I first discuss how suppletion can serve as an evaluative tool to identify morphological structure, drawing on Bobaljik's (2012) investigation into suppletion in adjectival paradigms (section 2.1) and my own research on suppletion in the nominal domain (section 2.2). In section 3, I start with a brief review of previous literature on the observation that the inclusive is more marked than the exclusive (Noyer 1992, Siewierska 2004, Cysouw 2003, a.o). Then, in section 3.2, I show that we find suppletion in the context of both the inclusive and the exclusive, as well as suppletion in the context of only the inclusive; however, the generalization that emerges is that suppletion in the context of only the exclusive is unattested (a potential counterexample from Dolakha Newar is discussed in section 3.4). In section 3.3, I discuss how this generalization supports the view that the inclusive is more marked than the exclusive, as well as arguing that, aside from being a structure detector, suppletion can also serve as an evaluative tool for identifying markedness relations. Finally, section 4 offers final remarks.

\section{Suppletion as a structure detector}

In this section, I briefly recapitulate Bobaljik (2012) and Moskal (2013), in which it is argued that suppletion data can serve as a detector of morphological structure. 


\subsection{Adjectival suppletion (Bobaljik 2012)}

In a study of 73 distinct adjectival cognate triples, Bobaljik (2012) shows that not all suppletion patterns in comparative morphology are attested. Specifically, we observe patterns such as in (4), however, whilst apparently legitimate and a priori conceivable, the pattern in (5) is unattested. ${ }^{3}$

$\begin{array}{lllll}\text { POSITIVE } & \text { COMPARATIVE } & \text { SUPERLATIVE } & & \\ \text { long } & \underline{\text { longer }} & \text { longest } & \text { AAA } & \\ \text { good } & \underline{\text { better }} & \underline{\text { best }} & \text { ABB } & \\ \text { bonus } & \underline{\text { melior }} & \text { optimus } & \text { ABC } & \text { (Latin) } \\ \text { *good } & \text { better } & \text { goodest } & \text { *ABA } & \end{array}$

Bobaljik shows that the absence of ABA patterns is accounted for if we assume (i) the containment hypothesis, and (ii) late insertion. Specifically, the containment hypothesis is formulated in (6):

(6) The containment hypothesis: The superlative always properly contains the comparative

In effect, (6) proposes that it is a universal property of languages that if there is a superlative in the structure, then there necessarily must be a comparative in the structure. That is, the structure for any given superlative is as in (7) below.

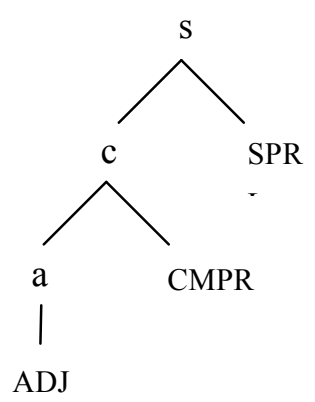

Indeed, in the following languages, the comparative is overtly contained within the superlative, showing the structure in (7) transparently:

3 Another unattested pattern is $\mathrm{AAB}$, where the superlative but crucially not the comparative is suppletive (e.g. *good-gooder-best). This is excluded by virtue of locality; in effect, if the comparative is not suppletive the superlative context is 'too far' from the root to cause suppletion. See Bobaljik (2012) for details. 


\begin{tabular}{|c|c|c|c|c|}
\hline & POS & CMPR & SPRL & \\
\hline Persian & $\underline{\mathrm{kam}}$ & kam-tar & kam-tar-in & 'little' \\
\hline Cimbrian & $\underline{\text { šüa }}$ & šüan-ar & šüan-ar-ste & 'pretty' \\
\hline Czech & mlad-ý & mlad-ší & nej-mlad-ší & 'young' \\
\hline
\end{tabular}

It is important to emphasize that the containment hypothesis posits that the comparative is always contained within the superlative; this means a structure such as in (9) is not a legitimate grammatical object by virtue of the universal hypothesis in $(6):^{4}$

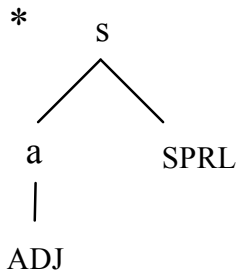

The second ingredient for ruling out the unattested ABA pattern is the assumption that syntactic structure is the input to morphology, which then has the task to convert syntactic structure into phonological material (Vocabulary Insertion, VI) (Distributed Morphology, DM; Halle \& Marantz 1993). Crucially, phonological substance is provided post-syntactically ('late insertion') and occurs cyclically starting from the most deeply embedded element.

In such a framework suppletion is modeled as contextual allomorphy: a feature (set) has a context-free default exponent, but in a more specific context a different exponent takes precedence (Bobaljik 2012). Consider the VI rules in (10) and (11) below; these are the rules that are relevant to the abstract item $\sqrt{G O O D}_{\text {. Whilst }}(11)$ has no restrictions with regard to its application, (10) applies in the context of the comparative.

$$
\begin{aligned}
& \sqrt{\text { GOOD }} \Leftrightarrow \text { be }(\mathrm{tt}) /_{-} \text {CMPR } \\
& \sqrt{\text { GOOD }} \Leftrightarrow \operatorname{good}
\end{aligned}
$$

4 Note that in a comparative structure, the superlative is not necessarily present; as such, a structure as in (i) is perfectly legitimate.

(i)

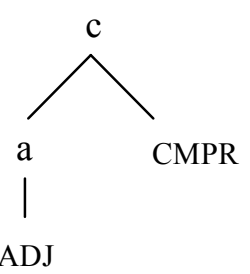


Furthermore, per the Elsewhere principle (Kiparsky 1973) the more specific VI rule in (10) will be preferred over the less specific VI rule in (11). That is, given that (10) makes reference to the more specific environment of the comparative, it must be employed in that context; the VI-rule in (11) will apply as a default but given the existence of the rule in (10) crucially not in the context of the comparative.

The containment hypothesis combined with late insertion gives us the tools to derive *ABA: given that precedence to the most specific VI rule must be given (late insertion) and each superlative must contain a comparative (containment hypothesis), if the comparative suppletes the superlative necessarily must do so too.

In sum, as we can see, suppletion data provides crucial evidence for the structure of adjectives, the containment hypothesis in particular.

\subsection{Nominal suppletion (Moskal 2013, to appear)}

Reporting on a study of some 80 languages, in Moskal (2013, to appear) I show that suppletion data from lexical nouns and pronouns reveals two asymmetries: (i) in lexical nouns numberdriven root suppletion is common while case-driven root suppletion is virtually unattested, and (ii) in contrast to lexical nouns, pronouns commonly supplete for both number and case.

Focusing first on lexical nouns, consider data from Ket (Werner 1997). In (12), we see some regular nouns in which the plural is expressed by a nasal suffix:

$\begin{array}{lll}\text { SG } & \text { PL } & \\ \text { am } & \text { ama-n } & \text { 'mother' } \\ \text { do?n } & \text { do?na-n } & \text { 'knife' } \\ \text { kyl } & \text { kyle-n } & \text { 'crow' }\end{array}$

In contrast, the nouns in (13) display root suppletion in the context of the plural; (the roots of) the singular forms bear no direct relation to (the roots of) the plural forms.

$\begin{array}{lll}\text { SG } & P L & \\ \text { orks' } & a^{2} q & \text { 'tree' } \\ \text { divl' } & k \wedge^{2} \mathrm{t} & \text { 'child' } \\ \mathrm{k} \varepsilon^{2} \mathrm{t} & \mathrm{d} \varepsilon^{2}-\eta & \text { 'man' }\end{array}$

The crucial contrast identified in Moskal (2013, to appear), though, is that whilst we see patterns as in (13) where a nominal root suppletes for number, nominal root suppletion in the context of case is virtually not observed. ${ }^{5}$

5 There are a few apparent counter-examples to the proposed ban on case-driven root-suppletion in lexical nouns: in Archi, we observe ábt:u 'father.ABS' vs. úmmu 'father.ERG', where the root of the lexical noun changes depending on which case it is in; however, Archi's father is a singulare tantum and in Moskal (to appear), I 
In contrast, in pronouns we see that suppletion can occur in the context of number as well as case. Consider data from Latvian (Mathaissen 1997); in (14), we see the familiar case of number-driven suppletion in second person pronouns: the pronominal stem in the singular is different from that in the plural.

$\begin{array}{lll} & \text { SG } & \text { PL } \\ \text { NOM } & \text { tu } & \text { jūs } \\ \text { DAT } & \text { tev } & \text { jums } \\ \text { ACC } & \text { tevi } & \text { jūs }\end{array}$

In (15), however, we also observe case-driven suppletion in first person pronouns in Latvian; that is, the pronominal stem not only differs depending on number information, but the pronominal stem in the first person singular is different depending on case: the nominative form es is different from that of the dative and accusative form $\operatorname{man}(i)$.

$\begin{array}{lll} & \text { SG } & \text { PL } \\ \text { NOM } & \text { es } & \text { mēs } \\ \text { DAT } & \text { man } & \text { mums } \\ \text { ACC } & \text { mani } & \text { mūs }\end{array}$

In Moskal (to appear, 2013), I argue that these asymmetries between lexical nouns and pronouns can be accounted for by their structural differences, combined with locality effects as proposed in DM, specifically, the cyclicity hypothesis.

Specifically, the structure of lexical nouns (16) and pronouns (17) is different in that the former have a root and a category defining node $n$ (standardly assumed in DM), whereas pronouns have less structure (Postal 1969, Longobardi 1994, Déchaine \& Wiltschko 2002), crucially lacking a root and category defining node. ${ }^{6}$ In (16) and (17) I furthermore assume Greenberg's Universal 39 and assume that number (\#) is located closer to the base than case (K).

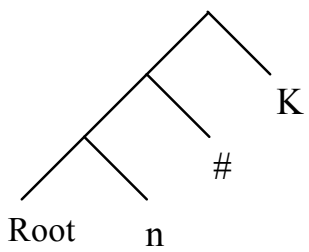

(17)

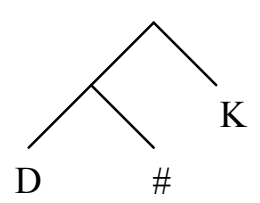

propose that Archi's 'father' is defective in that it lacks a number node. In essence, the lack of number opens up the possibility for (limited) case-driven root-suppletion; indeed, three other nouns that display case-driven rootsuppletion ('child' in Archi; 'water' and 'son' in Lezgian) are analysed in a similar way; see Moskal (to appear) for details.

6 Note that " $D$ " is merely used as a label here. 
Furthermore, DM assumes (some version of) the cyclicity hypothesis: that is, accessibility of structure is domain-dependent (Embick 2010, Bobaljik 2012). More specifically, certain nodes in the structure function as domain delimiters and morphological processes are confined to operate within this domain.

A natural choice of cyclic nodes would be category heads (Embick 2010). Then, on the assumption that cyclic heads induce spellout of their sister (Chomsky 2000, 2001), in the case of lexical nouns (16), $n$ causes spellout of the root. Furthermore, on the hypothesis that spellout immobilizes spelled out material (Embick 2010, Bobaljik 2000, 2012; see Scheer 2010 for an overview), the root would then be closed off for further interaction; this is represented in (18).

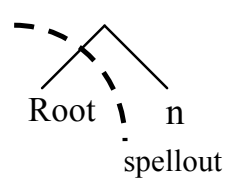

However, if that were the case, no allomorphy would ever cross a category-defining node, since the root would always be closed off (Embick 2010). Clearly, this is not correct, as evidenced in the case of number-driven (nominal) root suppletion, comparative-driven (adjectival) root suppletion, past-tense-driven (verbal) root suppletion, etc.

As such, the root needs to have access to a bit more structure. In Moskal (to appear, 2013), I propose that the relevant condition is 'morphological subjacency', where an element can establish a relation across one cyclic node, but not across two (or more) (cf. the syntactic subjacency condition, Chomsky 1973). ${ }^{7}$

Now, as represented in (19), under morphological subjacency number (\#) is accessible and a number value such as plural can govern suppletion of the root. However, case $(\mathrm{K})$ is too far removed at the point that the root is subject to VI and, as such, VI rules making reference to case values are uninterpretable.

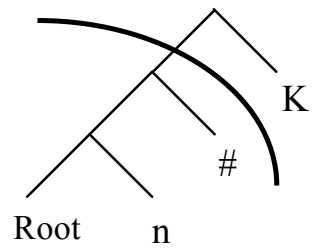

In contrast to lexical nouns, pronouns crucially lack a category-defining node in their structure; as such, no domain is created low in the structure and both number and case can potentially govern suppletion.

7 Morphological subjacency is used here for expository reasons; see Moskal (2013) for details, specifically with regard to the motivation of the locality restriction. 
(20)

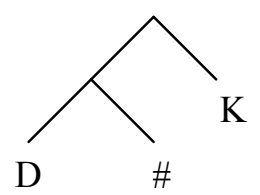

In sum, we again see, this time on the basis of suppletive items in the nominal domain, that suppletion data plays a crucial role in providing evidence for morphological structure as well as (the precise formulation of) the cyclicity hypothesis.

\section{$3 \quad$ Markedness and the inclusive/exclusive distinction}

\subsection{The inclusive is more marked}

Returning to the inclusive/exclusive distinction, morphological marking of inclusive and exclusive (first) person (plural) is relatively frequent cross-linguistically (Cysouw 2013). Either the inclusive form or the exclusive form can be morphologically marked (Harbour 2011). Indeed, in (21), we see that in Itzaj Maya (Hofling 2000) the inclusive has an additional morpheme -e'ex compared to the exclusive form.

$$
\begin{array}{ll}
\text { Inclusive } & \text { marking } \\
\text { PERSON } & \text { PL } \\
\text { 1EXCL } & \text { (in-)to'on } \\
\text { 1INCL } & \text { (in-)to'on-e'ex }
\end{array}
$$

In contrast, (22) we see that in Limbu (van Driem 1987) it is the exclusive that is expressed by an additional morpheme -ge compared to the inclusive form.

$$
\begin{array}{ll}
\text { Exclusive } & \text { marking } \\
\text { PERSON } & \text { PL } \\
\text { 1EXCL } & \text { angi-ge } \\
\text { 1INCL } & \text { angi }
\end{array}
$$

However, as noted by others, the first person inclusive is a marked category (Noyer 1992, Siewierska 2004, Cysouw 2003, a.o.). ${ }^{8}$ For instance, while exclusive marking is attested,

8 See Cormier (2005) for an opposing view where it is the exclusive that is more marked than the inclusive. She bases this on two aspects: (i) the prevalence of Australian languages to mark the exclusive with an additional morpheme (cf. data from Limbu in (22)); and (ii) the observation that in case a language loses the distinction between inclusive/exclusive it is overwhelmingly the inclusive category that survives (see also Lichtenberk 2005). However, the prevalence to mark the exclusive disappears when taking into account a broader set of languages (Harley \& Ritter 2002; see also LaPolla 2005). Secondly, the survival of the inclusive rather than the exclusive is a trend and not a universal, as exemplified by Lak, Ubykh, some Lezgic languages and Dargi 
inclusive marking seems to be much more common (see also Harley \& Ritter 2002); see also LaPolla (2005), who comes to a similar conclusion in a study on the inclusive/exclusive contrast in Tibeto-Burman languages. It is important to stress that whilst there is a clear trend towards inclusive marking as opposed to exclusive marking, both types of clusivity can be morphologically marked.

A further asymmetry between the inclusive and exclusive is noted by Cysouw (2013). There are a few languages that have a special pronoun for the inclusive, but the marking of the exclusive is identical to the first person singular (see also Sokolovskaya 1980); for instance, in Canela-Krahô (Popjes \& Popjes 1986), we see that the inclusive is expressed by $c u$ but for the singular as well as the (plural) exclusive the same morpheme is used: $w a$.

$\begin{array}{lllll}\text { Exclusive + 'I' } & & \\ \text { PERSON SG } & & \text { PL } \\ \text { 1EXCL } & & \text { wa } & \\ \text { 1INCL } & & \text { cu }\end{array}$

The situation where the exclusive is syncretic with the first person singular is relatively common; it has been attested among native American languages, the Papuan languages of New Guinea and there are various incidental examples (Cysouw 2005).

Conversely, the reverse situation is unattested: we do not observe the use of an identical morpheme for the (plural) inclusive and first person singular while having a separate special morpheme for exclusiveness. Note that in this case, it does not seem to be a trend but seems genuinely unattested. ${ }^{9}$

\subsection{Suppletion}

With regard to suppletion, we observe that suppletion can occur in the context of both the inclusive and exclusive, such as in e.g. Manam, Boumaa Fijian, Chamorro, amongst others. In (24), this is exemplified by Paraguayan Guaraní (Gregores \& Suárez 1967): both the exclusive form ore as well as the inclusive form yane are suppletive with respect to the first person singular form $\check{s} e$ (see also data from So in (3) above).

dialects (Lichtenberk 2005). In the following, I make a distinction between trends and universal patterns, focusing on the latter in this paper.

9 However, see Cysouw (2005) for a single purported case in Binandere where the suffixes for both first person singular and (plural) inclusive are -ana, while the suffix for the exclusive is -ara. This syncretism seems to be a recent development and Cysouw (2005:77) suggests it might be "an extension of an original first-person singular reference of -ana." 
Interestingly, though, we do identify an asymmetry between morphological inclusive and exclusive marking: whilst pronoun suppletion in the context of solely the inclusive is attested in a variety of languages, we do not seem to observe pronoun suppletion only in the context of the exclusive. Consider data from Evenki (Nedjalkov 1997) below in (25), in which we observe pronoun suppletion in the context of the inclusive but not in the context of the exclusive: the form for first person singular $b i$ is clearly related to the plural exclusive form $b u$ (cf. the singular/plural relation in second person: $s i$ vs. $s u$ ), however, the plural inclusive form mit bears no relation to the first person singular form $b i$.

(25) Suppletion in the context of inclusive

$\begin{array}{lll}\text { PERSON } & \text { SG } & \text { PL } \\ 1 & \text { bi } & \\ 1 \text { EXCL } & & \text { bu } \\ 1 \text { INCL } & & \underline{\text { mit }} \\ 2 & \text { si } & \text { su } \\ 3 & \text { nungan } & \text { nungartyn }\end{array}$

Indeed, whilst the pattern in (25) occurs in a variety of languages (e.g., Dumi, Sinangoro, Jarawara, Kwaza, amongst others), I have not found any language that displays the reverse situation. That is, we do not seem to find suppletion in the context of the exclusive without also having a suppletive variant in the inclusive (for an apparent counterexample, see section 3.4 on Dolakha Newar below). As such, we see that suppletion data show additional support for an asymmetry between the inclusive and exclusive.

\subsection{Markedness}

In this section, I argue that the discrepancy between only the inclusive being a potential context for suppletion, while only the exclusive is not, can be explained by assigning a bigger role to markedness in representations for person ( $c f$. Wiese 2005, and Bobaljik 2012). First consider the representations for person below (Bobaljik 2008; see also Harley \& Ritter 2002, Cysouw 2003, McGinnis 2005, Harbour 2011, a.o.): 


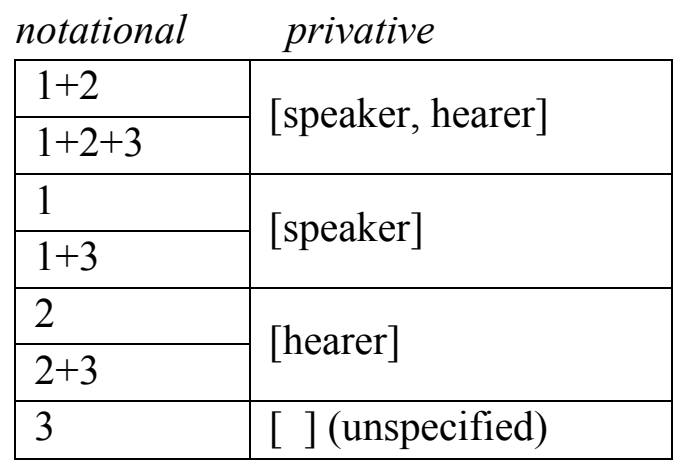

From the table in (26), it follows that the feature configuration for the inclusive, [speaker, hearer], is more marked than that for the exclusive, [speaker], since, crucially, the features characterizing the exclusive are contained within the more marked inclusive. As such, we can formulate a person markedness hierarchy for first person as follows: [speaker] (first person singular) being less marked than [speaker, plural] (exclusive) which in turn is less marked than [speaker, hearer, plural] (inclusive). ${ }^{10}$

Furthermore, in the area of phonology, Calabrese (2005) proposes that (phonological) processes can be sensitive to either marked features or both unmarked and marked features, but crucially not exclusively to unmarked features (see also, notably, Nevins 2010 for the same sensitivity restriction in the area of vowel harmony).

Extending this idea to the suppletion data in section 3.3, I suggest here that either marked person features can govern suppletion, or both unmarked and marked person features can govern suppletion, but unmarked person features cannot be the sole governors of suppletion (see also Calabrese 2008). As such, in languages where we observe suppletion for both the inclusive and the exclusive (such as Paraguayan Guaraní in (24) above), both unmarked (exclusive) and marked (inclusive) features are available to condition suppletion. In languages where suppletion only occurs in the inclusive (such as Evenki in (25) above), only the marked feature, inclusive, is salient and can govern suppletion. However, it is impossible for only exclusive to govern suppletion, since this would mean that only the unmarked feature would cause suppletion, but the marked value would not. That we do not find this state of affairs shows that suppletion is not only an identifier of morphological structure, but it is also an evaluative tool for identifying markedness relations.

An important question pertains to what can or cannot be sensitive to markedness relations. Indeed, we have seen that the overt realization of a morpheme for an unmarked (exclusive) or marked (inclusive) feature might display a trend towards expressing the marked rather than the unmarked feature, but it crucially is not a universal (see also footnote 9 above). In contrast, the suppletion data seem to constitute a discrete pattern of the pronominal base failing

10 Note that this cannot be captured as straightforwardly in a binary approach to person features. 
to undergo suppletion in the context of only the exclusive. ${ }^{11}$ What I propose here is that in operations that require accessibility of features, for instance to condition allomorphy (suppletion), we do not see tendencies but rather there are universal conditions. That is, reference to exclusively unmarked features is categorically ruled out: if a language suppletes for the exclusive (unmarked) feature it must necessarily supplete for the inclusive (marked) feature.

\subsection{Dolakha Newar}

In this section I discuss data from Dolakha Newar (Genetti 2007), which at first glance seems to constitute a counter-example to the claim that suppletion never occurs exclusively in the context of the exclusive. Consider the data in (27):

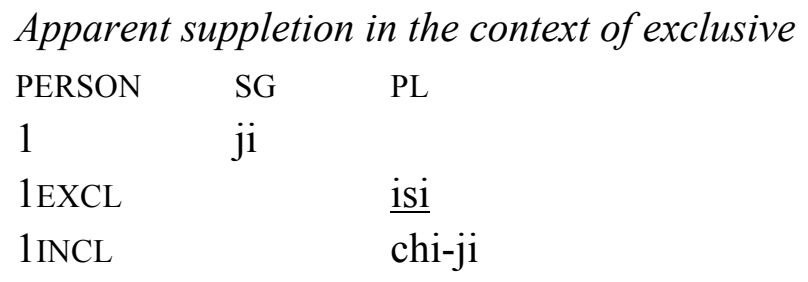

While the inclusive form chiji transparently contains the singular form $j i$ to which a prefix chi- is added, the exclusive seems to display a suppletive variant $i s i$.

Looking at the second person pronoun, however, given in (28), reveals that its form is the familiar prefix, chi. As such, the inclusive chiji form appears to be transparently composed of a morpheme hearer (chi) and a morpheme for speaker $(j i)$.

$\begin{array}{lll}\text { PERSON } & \text { SG } & \text { PL } \\ 2 & \text { chi } & \text { chi-pen }\end{array}$

As such, it seems that the inclusive is a compound pronoun of first and second person. Indeed, I suggest that the 'inclusive' has undergone morphological fission (see Arregi \& Nevins 2012 and references therein), splitting up a single feature bundle containing both hearer and speaker into two separate feature bundles [hearer] and [speaker]. ${ }^{12}$ This would lead to the following VI rules for the features discussed here:

11 Similarly, attested and unattested syncretism of first person singular with the inclusive and exclusive, respectively, seems another universal pattern (bar the case of Binandere, see footnote 10).

12 This analysis raises the question about the exponent of the plural feature in the inclusive form. At this point, I suggest that the plural deletes in the relevant context (note also that a form which is composed of speaker and hearer is necessarily non-singular, see also below on minimal/augmented systems); and I leave the details of the analysis for Dolakha Newar, as well as the relation between the inclusive and second person in general, for future research. Relevant here is that Dolakha Newar does not constitute a clear counter-example to the claim that suppletion never occurs only in the context of the exclusive. 


$$
\begin{aligned}
& {[1, \mathrm{PL}] \Leftrightarrow \mathrm{isi}} \\
& {[1] \Leftrightarrow \mathrm{ji}} \\
& {[2] \Leftrightarrow \mathrm{chi}} \\
& {[\mathrm{PL}] \Leftrightarrow \text { pen }}
\end{aligned}
$$

Consequently, Dolakha Newar can be analyzed as a Paraguayan Guaraní style language in which both marked and unmarked features are salient context to govern suppletion, but since we do not see the inclusive represented on a single morpheme it does not surface as suppletive. In effect, fission of the inclusive bleeds suppletion of the inclusive. As such, Dolakha Newar does not constitute a convincing counter-example to the claim proposed here.

\section{$4 \quad$ Final remarks}

In the above discussion, I argued that suppletion is an evaluative tool to identify limits on accessibility to condition allomorphy, not only in the sense of revealing morphological structure but I also extended Calabrese's proposal to suppletion, arguing that allomorphy can be sensitive to either marked features or both unmarked and marked features, but crucially not exclusively to unmarked features. Specifically, the sensitivity operates at the level of vocabulary insertion, which is inherently a morpho-phonological process. However, it seems to be a more general property of morphology (see also Calabrese 2008); indeed, the observation that the singular can be syncretic with the exclusive but not with the inclusive (section 3.1) suggests that operations such as impoverishment are sensitive to the distinction as well.

Furthermore, we have seen that the overt realization of a morpheme for an unmarked (exclusive) or marked (inclusive) feature might display a trend towards expressing the marked rather than the unmarked feature. In contrast, in operations that require accessibility of features we do not see tendencies but universal conditions, such as reference to exclusively unmarked features being categorically ruled out.

Whilst the generalization identified in this paper is clear, there are a number of avenues to explore further. Specifically, another are of investigation would include dual (and trial) number, in addition to singular and plural. Furthermore, while I have focused on the traditional inclusive/exclusive contrast in this paper, there are more fine-grained distinctions (see Siewerska \& Bakker 2005), which could reveal further patterns. In particular, languages that display a minimal/augmented contrast require further scrutiny. Finally, I have only focused on free pronouns, but the inclusive/exclusive contrast is also attested in various agreement morphemes, such as verbal agreement markers.

\section{$5 \quad$ References}

Arregi, K. and Nevins, A. 2012. Morphotactics: Basque auxiliaries and the structure of spellout. Dordrecht: Springer. 
Bobaljik, J. 2008. Missing Persons: A Case study in Morphological Universals. The Linguistic Review, special theme issue Examples of Linguistic Universals 25.1-2:203-230.

Bobaljik, J. 2012. Universals in Comparative Morphology. Cambridge, MA: MIT Press.

Calabrese, A. 2005. Markedness and Economy in a Derivational Model of Phonology, Berlin: Mouton de Gruyter.

Calabrese, A. 2008. On absolute and contextual syncretism: Remarks on the structure of case paradigms and on how to derive them. In Inflectional Identity, Bachrach and Nevins (eds).

Chomsky, N. 1973. Conditions on transformations. In A Festschrift for Morris Halle, New York: Holt, Reinhart and Winston.

Chomsky, N. 2000. Minimalist inquiries. In R. Martin, D. Michaels and J. Uriagereka, (eds.), Essays on minimalist syntax in honor of Howard Lasnik. MIT Press, 89-155.

Chomsky, N. 2001. Derivation by phase. In M. Kenstowicz, (ed.), Ken Hale: A life in language. MIT Press, 1-52.

Corbett, G. 2007. Canonical typology, suppletion and possible words. Language 83(1): 8-42.

Cormier, K. 2005. Exclusive pronouns in American Sign Language. In E. Filimonova (Ed.), Clusivity; typology and case studies of the inclusive-exclusive Filimonova distinction (pp. 231-258). Amsterdam: John Benjamins.

Cysouw, M. 2003. The paradigmatic structure of person marking, Oxford University Press, Oxford.

Cysouw. M. 2005. Syncretisms involving clusivity. In E. Filimonova (Ed.), Clusivity; typology and case studies of the inclusive-exclusive Filimonova distinction (pp. 73-112). Amsterdam: John Benjamins.

Cysouw, M. 2013. Inclusive/Exclusive Distinction in Independent Pronouns. In: Dryer, Matthew S. \& Haspelmath, Martin (eds.) The World Atlas of Language Structures Online. Leipzig: Max Planck Institute for Evolutionary Anthropology.

Déchaine, R.-M. and M. Wiltschko. 2002. Decomposing pronouns. Linguistics Inquiry, 33(3): 409-422.

Driem, G. van. 1987. A Grammar of Limbu. Berlin: Mouton de Gruyter.

Embick, D. 2010. Localism versus Globalism in Morphology and Phonology. MIT Press.

Filimonova, E. (ed.). 2005. Clusivity: Typology and case studies of the inclusive-exclusive distinction, John Benjamins, Amsterdam.

Genetti, C. 2007. A Grammar of Dolakha Newar. Berlin: Mouton de Gruyter.

Gregores, E. and J. Suárez. 1967. A Description of Colloquial Guaraní. The Hague: Mouton.

Halle, M. and A. Marantz. 1993. Distributed Morphology and the Pieces of Inflection. In K. Hale and S. Keyser, (eds.), The View from Building 20. Cambridge, MA: MIT Press, 111-176.

Harbour, D. 2011. The architecture of features and the derivation of person. Ms.

Harley, H. and E. Ritter (2002). Person and number in pronouns: A feature-geometric analysis. Language 78: 482-526. 
Hippisley, A., M. Chumakina, G. Corbett and D. Brown. 2004. Suppletion: frequency, categories and distribution of stems. Studies in Language 28(2): 387-418.

Hofling, C. 2000. Itzay Maya Grammar. University of Utah Press.

Kiparsky, P. 1973. "Elsewhere" in phonology. In A Festschrift for Morris Halle, New York: Holt, Reinhart and Winston, 93-106.

LaPolla, R. 2005. The inclusive-exclusive distinction in Tibeto-Burman languages. In E. Filimonova (Ed.), Clusivity; typology and case studies of the inclusive-exclusive Filimonova distinction (pp. 291-312). Amsterdam: John Benjamins.

Lichtenberk, F. 2005. Inclusive-exclusive in Austronesian: An opposition of unequals. In E. Filimonova (Ed.), Clusivity; typology and case studies of the inclusive-exclusive Filimonova distinction (pp. 261-290). Amsterdam: John Benjamins.

Longobardi, Giuseppe. 1994. Reference and proper names: A theory of N- movement syntax and logical form. Linguistic Inquiry 25: 609-665.

Mathaissen, T. 1997. A short grammar of Latvian. Bloomington, IN: Slavica Publishers.

McGinnis, M. 2005. On markedness asymmetries in person and number. Language 81, 699-718.

Moskal, B. 2013. A Case Study in Nominal Suppletion, ms. University of Connecticut.

Moskal, B. to appear. The Curious Case of Archi's father. The Proceedings of the 39th Berkeley Linguistics Society.

Nedjalkov, I. 1997. Evenki. Routledge Descriptive Grammars. London / New York: Routledge.

Nevins, A. 2010. Locality in vowel harmony. MIT Press.

Noyer, R. 1992. Features, Positions and Affixes in Autonomous Morphological Structure. MIT dissertation.

Popjes, J. and J. Popjes. 1986. Canela-Krahô. In Derbyshire, Desmond C. and Pullum, Geoffrey K. (eds.), Handbook of Amazonian Languages 1, 128-199. Berlin: Mouton de Gruyter.

Postal, P. 1969. On so-called "pronouns" in English. In D. Reibel and S. Schane (eds), Modern Studies in English. Englewood Cliffs, NJ: Prentice-Hall, 201-224.

Scheer, T. (2010) A Guide to Morphosyntax-Phonology Interface Theories. Berlin: Mouton de Gruyter.

Siewerska, A. 2004. Person. Cambridge University Press.

Siewerska, A. and D. Bakker. 2005. Inclusive/exclusive in free and bound person forms. In E. Filimonova (Ed.), Clusivity; typology and case studies of the inclusive-exclusive Filimonova distinction (pp. 151-178). Amsterdam: John Benjamins.

Sokolovskaya, N. 1980. Nekotorye semantičeskie universalii v sisteme ličnyx mestoimenij (Some semantic universals in systems of personal pronouns). In I.F. Vardul' (Ed.), Teorija i tipologija mestoimenij, 84-103. Moskva: Nauka.

Werner, H. 1997. Die Ketische Sprache. Wiesbaden: Harrassowitz Verlag.

Wiese, B. 2005. Form and function of verb ablaut in contemporary standard German. In Studies in Integrational Linguistics, Robin Sackmann, ed., Amsterdam: John Benjamins. 